\title{
The Effect of Aminophylline on Quinidine Passage into the Central Nervous System of Rats
}

\author{
Velibor Vasović ${ }^{1 *}$, Nebojša Stilinovićc ${ }^{1}$, Saša Vukmirović ${ }^{1}$, Ivan Mikov², Jelena Ćalasan ${ }^{3}$, Momir Mikov $^{1}$ \\ ${ }^{1}$ Department of Pharmacology and Toxicology, Faculty of Medicine, University of Novi Sad, REPUBLIC OF SERBIA. \\ 2Department of Occupational Medicine, Faculty of Medicine, University of Novi Sad, REPUBLIC OF SERBIA. \\ ${ }^{3}$ Department of Nutrition and Immunology, Technische Universität München, Freising-Weihenstephan, GERMANY.
}

\begin{abstract}
Background and Objective: There is significant interest in mutual influence of substances during their passage into the central nervous system (CNS). Quinidine is a drug which can achieve significant concentration in CNS and cause side effects and aminophylline is a drug with possibility to change distribution of drugs in CNS. Thus the aim of this work was to study the effect of aminophylline on the transition of quinidine through the bloodbrain barrier into the central nervous system. Material and Methods: The experiments were carried out on Wistar rats, which received quinidine in the form of the retrograde intra-arterial bolus injection into the right axillary vein. The control group of animals received subcutaneously physiological solution $30 \mathrm{~min}$ before the intra-arterial quinidine application, whereas the test group animals also received subcutaneously aminophylline 30 min before quinidine application. The rats were sacrificed by decapitation in specified time intervals in order to determine quinidine concentration in different parts of CNS. Results: There were no significant changes in serum quinidine levels by comparing the results of experimental group with those of the control group of animals. In all parts of CNS aminophylline pre-treatment caused significant decrease in CNS quinidine concentration. Conclusion: The results suggest that co-administration of aminophylline and quinidine, decreases quinidine concentrations in the CNS of rats.
\end{abstract}

Key words: Aminophylline, Quinidine, Blood-brain barrier, Drug interactions.

\section{INTRODUCTION}

The problem of selective permeability of blood-brain barrier (BBB), as also investigation of mutual influence of substances during their passage into the CNS, represents huge challenge of modern scientific work. Nowadays, it is well-known that BBB is formed by tight junctions between adjacent capillary endothelial cells and it represents diffusion barrier for many polar molecules. Molecules passage through semi-selective cell barrier like this evolves sometimes through specific protein carriers, which form transport system of membrane. ${ }^{1-4}$

Some molecules can cross into the brain against concentration gradient with help of specific protein carriers and adenosine triphosphate (ATP) consumption. On the other hand, the same mechanism is employed for drug efflux as a protection of accumulating potentially toxic substances. One of the efflux transporters is P-glycoprotein (P-gP), which is ATP-dependent and encoded by multidrug resistance 1/ATP-binding cassette sub-family B1 (MDR1/ABCB1) gene. P-gp is present in the apical membranes of endothelial cells of $\mathrm{BBB}$ and some substances can inhibit its function. ${ }^{4-6}$ Quinidine is a member of the first generation P-gp inhibitors and it has been widely used as an $\mathrm{ABCB} 1$ probe for testing drug interactions at the BBB. ${ }^{7}$ Since quinidine is in the same time a substrate for P-gp, it interacts with the P-gp like potent and efficient inhibitor and prevents its own transepithelial transport in basolateral to apical membrane direction. This leads to
Submission Date: 24-05-2017; Revision Date: 06-07-2017; Accepted Date: 10-01-2018

DOI: 10.5530/ijper.52.1.16 Correspondence: Velibor Vasović,

Department of Pharmacology and Toxicology, Faculty of Medicine, Novi Sad, Hajduk Veljkova 321000 Novi Sad, REPUBLIC OF SERBIA.

Phone: +381-21-522-172

Fax: +381-21-661-5771

Email: velibor.vasovic@ mf.uns.ac.rs



www.ijper.org 
increased CNS concentrations of quinidine which can result in its CNS side effects. ${ }^{7-10}$

The main source for altered effects of drugs on the CNS lies in the dynamic interaction between plasma and the specific transporters on BBB. Beside this fact, drug-drug interactions at the site of $\mathrm{BBB}$ can theoretically involve several other mechanisms; such would be change in cerebral blood flow $(\mathrm{CBF})$ and circulation in general. ${ }^{10,11}$ Aminophylline is the example of drug that can affect both cerebral and body circulation. It is competitive nonselective phosphodiesterase (PDE) inhibitor and nonselective adenosine receptor antagonist. Despite its adenosine antagonism, and expected reduction of cerebral blood flow, aminophylline has been associated with no change or increase in blood flow at the same place also. ${ }^{12,13}$

In this study we have investigated the mechanism how aminophylline alters kinetics of the drug which can attain its concentration in CNS, after the sequential application of single dose of these drugs. Thus, the aim of the study was to investigate how aminophylline, administered subcutaneously, affects quinidine passage into CNS after its retrograde intra-arterial application into the right axillary artery.

\section{MATERIALS AND METHODS}

\section{Drugs and Chemicals}

Quinidine sulphate, aminophylline and urethane were of HPLC grade and purchased from Sigma Chemical Co. (Steinheim, Germany). All other substances used in this study were of analytical grade.

\section{Experimental Animals}

Experiments were carried out on adult sexually mature, both sexes, Wistar rats, weighing 250-350 g which were bred at the Military Academy of Medicine and housed at the Department of Pharmacology, Toxicology and Clinical Pharmacology, Medical Faculty, University of Novi Sad. The experimental procedures were conducted in accordance with the European Directive (2010/63/ EU) for animal experiments and they were reviewed and approved by Ethics Committee for Protection and Welfare of Experimental Animals at University of Novi Sad, Serbia.

To introduce the drug into bloodstream allowing to be transported to the CNS, catheterization of the right axillary artery was performed. In mammals, analogous to human vasculature structure, there are three branches of ascending aorta: brachiocephalic artery, left common carotid artery and left subclavian artery. Ten millimetres from the beginning of aorta, starts the branch of brachiocephalic artery, which bifurcates after four millimetres to right subclavian artery and right common carotid artery. The axillary artery is the largest branch of subclavian artery, and the catheter tip reaches the point where this artery enters the chest. ${ }^{14,15}$ Due to brachiocephalic artery, the substance injected through the catheter into the axillary artery, is within approximately $15 \mathrm{~s}$ in brain circulation thanks to the action of heart pump.

\section{Experimental Design}

The animals were divided into two groups, each consisting of 30 rats. The first (control) group received physiological solution subcutaneously $30 \mathrm{~min}$ before intra-arterial application of quinidine at a dose of $25 \mathrm{mg} / \mathrm{kg}$ b.w. The second (experimental) group was received aminophylline in a dose of $23 \mathrm{mg} / \mathrm{kg}$ b.w. subcutaneously $30 \mathrm{~min}$ before intra-arterial application of quinidine.

Prior to preparation of the blood vessels, the rats were anaesthetized with urethane, administered intraperitoneally (i.p.) at a dose of $4 \mathrm{ml} / \mathrm{kg}$ b.w. When the animals had been anesthetized the next step was preparation of left jugular vein and right axillary artery. Quinidine was then introduced via catheterization into the right axillary artery for a $15 \mathrm{~s}$ period. Thirty minutes before this procedure the animals in the control group had received physiological solution s.c., and those in the test group had received aminophylline in the above mentioned doses.

At the time intervals of 30, 60, 90, 120 and $240 \mathrm{~s}, 0.1 \mathrm{ml}$ blood samples were taken from the left jugular vein. The blood was transferred into tubes containing $1 \mathrm{ml}$ of distilled water, so that a dilution of 1:10 was obtained. The samples were stored at $-20^{\circ} \mathrm{C}$ until the determination of quinidine concentrations.

After taking the blood samples from left jugular vein, to reduce the amount of blood in the blood vessels of the brain, the CNS was rinsed with $5 \mathrm{ml}$ of distilled water injected into the left ventricle of the heart. Then rats were sacrificed by decapitation at the same time intervals as in the case of blood sampling. By resecting the cranial bones, the brain tissue was made accessible, and was divided into the following compartments: cerebellum, brainstem (truncus encephalicus), left and right cerebral hemisphere. For the quinidine extraction from blood and brain we used Kramer and Isakson method. ${ }^{16}$ Quinidine concentrations in blood and brain were measured with standard spectrophotofluorimetric method, for both control and experimental animals. ${ }^{16,17}$

\section{Statistical Analysis}

Statistical analysis was carried out with Microsoft Excel program for Windows, ver. 2010. All data were reported 
as mean values \pm standard deviation (SD). Comparisons between two groups were performed using Student's t-test for independent samples. A difference was considered to be statistically significant for a $p$-value lower than $0.05(\mathrm{p}<0.05)$.

\section{RESULTS}

The highest quinidine concentration in the blood of the experimental animals was recorded at the $30^{\text {th }} \mathrm{s}$ after drug application $(18.94 \mu \mathrm{g} / \mathrm{g})$. Afterwards, sudden decrease in concentration was observed, but at the $90^{\text {th }}$ and the $120^{\text {th }}$ s level was approximately the same $(7.50 \mu \mathrm{g} / \mathrm{g})$. After the $120^{\text {th }} \mathrm{s}$, the concentration of quinidine again decreased, reaching in $240^{\text {th }} \mathrm{s}$ value of $2.89 \mu \mathrm{g} / \mathrm{g}$ (Figure 1).

Comparing the results of experimental group with those of the control group, higher quinidine concentrations in the blood of test group animals were recorded in all tested intervals. Beside the previously mentioned fact, according to a Student's t-test, aminophylline did not significantly change quinidine concentrations in any of the investigated time intervals.

Compared with control group, blood/brain stem ratio of quinidine concentration was higher in experimental group in all tested time intervals. Statistical significant difference was achieved at the $90^{\text {th }}, 120^{\text {th }}$ and $240^{\text {th }} \mathrm{s}$ with $p<0.05$ (Figure 2).

Compared with control group, blood/cerebellum ratio of quinidine concentration is higher in experimental group in all tested time intervals under aminophylline influence. According to the t-test difference was statistically significant at the $60^{\text {th }} \mathrm{s}$ with $p<0.01$, and at the $90^{\text {th }}$ and $120^{\text {th }}$ s with $p<0.05$ (Figure 3).

Same as for previous parts of CNS, blood/right brain hemisphere ratio of quinidine concentration is higher in the experimental group of animals comparing it with control group. According to the t-test, it was observed that difference was statistically significant at the $90^{\text {th }}$ and $120^{\text {th }} \mathrm{s}$ with $p<0.05$ (Figure 4).

In Figure 5 can be seen that for this part of CNS quinidine concentration ratio is higher, influenced by aminophyllin pre-treatment. According to the t-test, it was observed that difference was statistically significant at the $120^{\text {th }} \mathrm{s}$ with $p<0.05$.

\section{DISCUSSION}

As we stated in the introduction part this work was studying quinidine, a substance which can pass through $\mathrm{BBB}$ and attain its level in CNS during time. Moreover, we were studying aminophylline, a substance that can

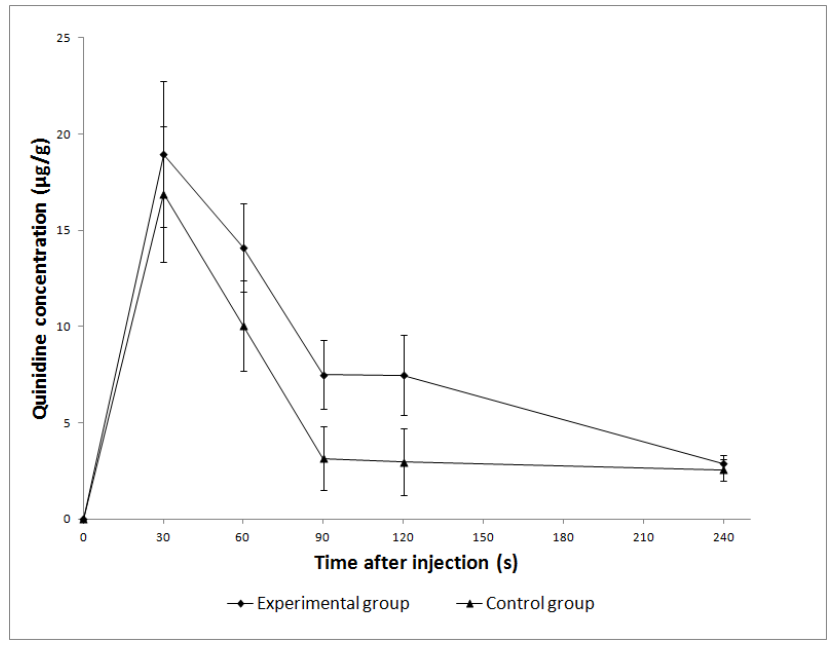

Figure 1: Quinidine concentration in the blood of animals pre-treated with saline solution (control group) and aminophylline (experimental group) (mean $\pm S D ; n=30$ per group).

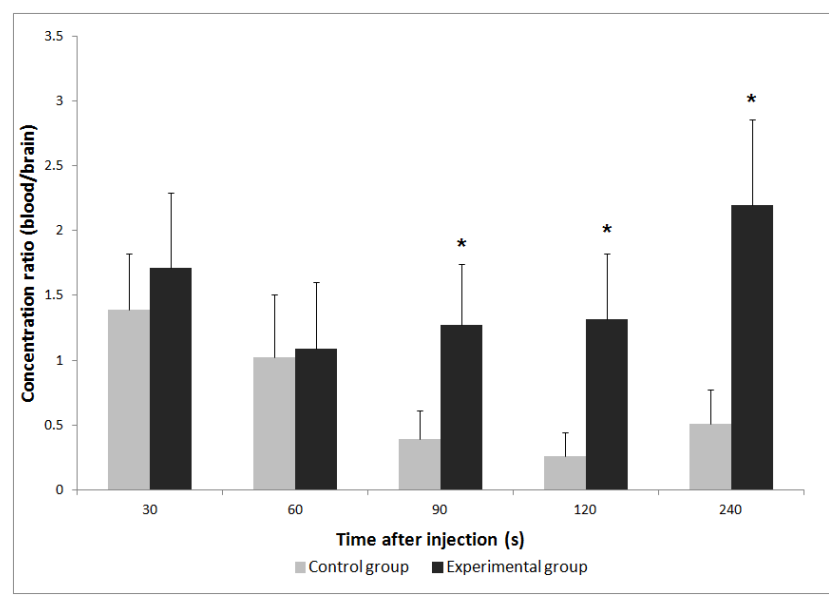

Figure 2: Concentration ratio of quinidine in blood and brain stem of the control and experimental group of animals (mean \pm SD; $\$ p<0.05$ vs control; $n=30$ per group).



Figure 3: Concentration ratio of quinidine in blood and cerebellum of the control and experimental group of animals (mean $\pm \mathrm{SD} ; \S p<0.05$ vs control, $+p<0.01$ vs control; $n=30$ per group). 




Figure 4: Concentration ratio of quinidine in blood and right brain hemisphere of the control and experimental group of animals (mean $\pm S D ; \S p<0.05$ vs control; $n=30$ per group).

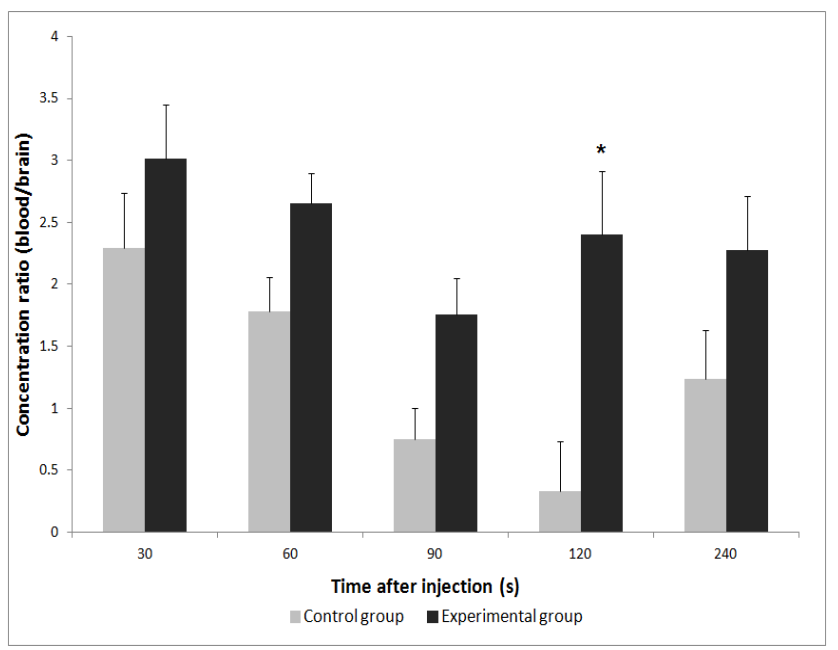

Figure 5: Concentration ratio of quinidine in blood and left brain hemisphere of the control and experimental group of animals (mean $\pm S D ; n=30$ per group).

change quinidine pharmacokinetics, according to our previous investigations ${ }^{8,9,18,19}$ In the control group of animals, experiment showed that the quinidine maximal blood concentration was recorded at the $30^{\text {th }} \mathrm{sec}$. After that time it rapidly decreased and from the $90^{\text {th }}$ sec it kept at approximately same level. The explanation for this situation is in quinidine liposolubility and the fact that it permeates more easily into lipid-rich tissues, like CNS structures. ${ }^{7-9,19}$ The same was observed for experimental group of animals which were pre-treated with aminophylline. In $30^{\text {th }}$ sec quinidine reached maximal blood concentration. Afterwards, sudden decrease in quinidine blood concentration was noticed in $60^{\text {th }} \mathrm{sec}$ with slowing down of that process after $90^{\text {th }}$ sec. By comparing those two groups, it can be seen that aminophylline increased quinidine concentration in the blood, but that difference was without statistical significance. It has been well-recognized that drug-drug interactions can affect the distribution of drugs into a particular compartment resulting in change of their systemic blood concentration. In addition, drug-drug interactions can result in drug effects on organs that normally are not their target.s ${ }^{10,11}$ In this case aminophylline, a PDE3 and PDE4 inhibitor, showed tendency to keep quinidine in systemic circulation. PDE inhibition is leading to relaxation of vasculature smooth muscles which causes hypotension as a side effect of a therapy with aminophylline. That effect could contribute to higher quinidine concentration in blood, as well as many other effects. ${ }^{12,13,20}$ Keeping in mind results of studies with aminophylline effects on $\mathrm{CBF}$, we have tried to go further in explanation of this possibly interesting interaction.

Blood/brain ratio was used for demonstration of aminophylline effect on quinidine passage into certain parts of CNS. It shows what was the actual amount of drug that passed from blood into CNS. ${ }^{18,19}$

As it was expected from the results of our previous study, aminophylline decreased quinidine passage from blood to brain stem and that was expressed in almost all of the tested time intervals (Figure 2). ${ }^{18}$ Same was observed for cerebellum and ipsilateral part of brain (same side as for quinidine administration). Quinidine transition from blood to CNS structures significantly decreased under aminophylline influence, in all tested time intervals. Same was noticed for contralateral part of brain, with statistically significant change in $120^{\text {th }} \mathrm{s}$ only. These divergences in quinidine kinetics of particular parts of brain can be explained with a differences in perfusion rate and regional drug exposure. ${ }^{21}$

Lower ratio values of quinidine concentration for the brain stem, cerebellum, left and right brain hemisphere of control animals were achieved because of unchanged quinidine penetration into CNS structures via its special transporters. So, the quinidine concentrations in blood and CNS were similar leading to lower ratio values. Beside P-gp, quinidine is also a substrate and inhibitor of organic cation transporters family (OCT), which are influx transporters. ${ }^{22}$ Members of the OCT family have been molecularly identified in CNS structures and endothelial cells of rats, rabbits and humans. ${ }^{23-25}$ In vitro model of Xenopus oocytes, expressed with human OCTN1 transporter subtype, showed that quinidine is a good substrate for OCTN1. Through that transport quinidine achieves significant CNS concentrations rapidly. ${ }^{22}$ Aminophylline decreased quinidine transport from blood to different parts of CNS, probably by 
affecting cerebral blood flow, or to be precise, by slowing the circulation in that part of rat's organism. As we stated in the introduction part, aminophylline decreases cerebral blood flow through adenosine receptor antagonism. Adenosine is a potent cerebral vasodilator and by antagonizing its action aminophylline can change CNS distribution of any drug. Considering adenosine antagonism and PDE inhibition as well, it is obvious that aminophylline can change quinidine distribution. ${ }^{12,13,19}$ Despite that fact, maybe there are some other possible ways of quinidine and aminophylline interaction. Further research should investigate if there is a competitive antagonism between quinidine and aminophylline for transport on BBB through OCT, because they are both organic cations.

\section{CONCLUSION}

It can be concluded that co-administration of aminophylline and quinidine, decreases quinidine concentrations in the CNS of rats. On contrary, aminophylline has no influence on quinidine blood concentrations. At the end, this study is pointing out to possible clinical significance of aminophylline interaction with drugs that pass into CNS and have desired or undesired effects on that system.

\section{REFERENCES}

1. Stamatovic SM, Johnson AM, Keep RF, Andjelkovic AV. Junctional proteins of the blood-brain barrier: New insights into function and dysfunction. Tissue Barriers. 2016; 4(1)., e1154641.

2. Freese C, Hanada S, Fallier-Becker P, Kirkpatrick CJ, Unger RE. Identification of neuronal and angiogenic growth factors in an in vitro blood-brain barrier model system: Relevance in barrier integrity and tight junction formation and complexity. Microvasc Res. 2017; 111:1-1.

3. Liu WY, Wang ZB, Zhang LC, Wei X, Li L. Tight junction in blood-brain barrier: an overview of structure, regulation, and regulator substances. CNS Neurosci Ther. 2012; 18(8):609-15.

4. Gao W, Liu Y, Jing G, Li K, Zhao Y, Sha B, et al. Rapid and efficient crossing bloodbrain barrier: Hydrophobic drug delivery system based on propionylated amylose helix nanoclusters. Biomaterials. 2017; 113:133-44.

5. Upton RN. Cerebral uptake of drugs in humans. Clin Exp Pharmacol Physiol. 2007; 34(8):695-701.

6. Haiying S, Haiqing D, Naveed S, Elmquist WF. Drug efflux transporters in the CNS. Adv Drug Deliver. 2003; 55(1):83-105.

7. Sziráki I, Erdő F, Beéry E, Molnár PM, Fazakas C, Wilhelm I, et al. Quinidine as an ABCB1 Probe for Testing Drug Interactions at the Blood-Brain Barrier An In Vitro In Vivo Correlation Study. J Biomol Screen. 2011; 16(8):886-94.
8. Srivalli KMR, Lakshmi PK. Overview of P-glycoprotein inhibitors: a rational outlook. Rev Bras Cienc Farm. 2011; 16(8):886-94.

9. Kusuhara $H$, Suzuki $H$, Terasaki $T$, Kakee $A$, Lemaire $M$, Sugiyama $Y$. P-Glycoprotein mediates the efflux of quinidine across the blood-brain barrier. J Pharmacol Exp Ther. 1997; 283(2):574-80.

10. Endres CJ, Hsiao P, Chung FS, Unadkat JD. The role of transporters in drug interactions. Eur J Pharm Sci. 2006; 27(5):501-17.

11. Eyal S, Hsiao P, Unadkat JD. Drug interactions at the blood-brain barrier: fact or fantasy? Pharmacol Therapeut. 2009; 123(1):80-104.

12. McDonnell M, Ives NK, Hope PL. Intravenous aminophylline and cerebral blood flow in preterm infants. Arch Dis Child. 1992; 67(4):416-8.

13. Sulek CA, Blas MA, Lobato EB. Milrinone increases middle cerebral artery blood flow velocity after cardiopulmonary bypass. J Cardiothor Vasc An. 2002; 16(1):64-9.

14. Taira $Y$, Marsala M. Effect of proximal arterial perfusion pressure on function, spinal cord blood flow, and histopathologic changes after increasing intervals of aortic occlusion in the rat. Stroke.1996; 27(10):1850-8.

15. Farkas E, Luiten PGM, Bari F. Permanent, bilateral common carotid artery occlusion in the rat: a model for chronic cerebral hypoperfusion-related neurodegenerative diseases. Brain Res Rev. 2007; 54(1):162-80.

16. Cramér $\mathrm{G}$, Isaksson $B$. Quantitative determination of quinidine in plasma. Scand J Clin Lab Inv.1963; 15(5):553-6.

17. Rubin M. Fluorometry in clinical chemistry, analytical techniques and procedures. TheAminco spectrophotofluorometer and fluoromicrophotometer. Silver Spring, Maryland: American Instrument Company Inc.; 1965.

18. Vasović $\mathrm{V}$, Banić $\mathrm{B}$, Jakovljević $\mathrm{V}$. Effect of caffeine on quinidine transport to the central nervous system in rats. J Basic Clin Physiol Pharmacol. 2007; 18(1):1-10.

19. Vasović V, Banić B, Jakovljević V, Tomić Z, Milić-Djordjević V. Effect of aminophylline on aspirin penetration into the central nervous system in rats. Eur J Drug Metab Pharmacokinet. 2008; 33(1):23-30.

20. Barnes PJ. Theophylline: new perspectives for an old drug. Am J Resp Crit Care. 2003; 167(6):813-8.

21. Zhao R, Pollack GM. Regional differences in capillary density, perfusion rate, and P-glycoprotein activity: A quantitative analysis of regional drug exposure in the brain. Biochem Pharmacol. 2009; 78(8):1052-9.

22. Tsuji A. Influx transporters and drug targeting: Application of peptide and cation transporters. Int Congr Ser. 2005; 1277:75-84.

23. Dickens D, Owen A, Alfirevic A, Giannoudis A, Davies A, Weksler B, et al. Lamotrigine is a substrate for OCT1 in brain endothelial cells. Biochem Pharmacol. 2012; 83(6):805-14.

24. Tsuda M, Terada T, Ueba M, Sato T, Masuda S, Katsura T, et al. Involvement of human multidrug and toxin extrusion 1 in the drug interaction between cimetidine and metformin in renal epithelial cells. J Pharmacol Exp Ther. 2009; 329(1):185-91.

25. Ming X, Ju W, Wu H, Tidwell RR, Hall JE, Thakker DR. Transport of dicationic drugs pentamidine and furamidine by human organic cation transporters. Drug Metab Dispos.2009; 37(2):424-30.

Cite this article: Vasovic V, Stilinovic N, Vukmirovic S, Mikov I, Calasan J, Mikov M. The Effect of Aminophylline on Quinidine Passage into the Central Nervous System of Rats. Indian J of Pharmaceutical Education and Research. 2018;52(1):146-50. 